\title{
Subcooled Flow Boiling of Water enhancement by Using Internal Surface Coating
}

\author{
Ahmed Y. Abdel Azim, Abdalla S. Hanafy, and Essam E Khalil * \\ Department of Mechanical Engineering, Cairo University, Cairo, Egypt
}

\begin{abstract}
The main objective of the present work, is to study the effect of coating on boiling heat transfer of compressed water entering a vertical tube and leaving at near saturated vapor conditions, while the tube is heated with stream of cross flow hot gases. This is carried out by employing different types of internal tube coatings with different surface roughnesses and thicknesses. Numerical investigation is carried out by using software called EES (Engineering Equation Solver). It is concluded that, the heat transfer enhancement over the smooth tube case reaches $34.063 \%$ for the heat transfer coefficient while the pressure drop is higher than that in the case of smooth tube by $64.64 \%$.
\end{abstract}

Keywords: Flow Boiling, Pressure Drop, Internal Surface Coating.

\section{Introduction}

Boiling is the process of rapidly converting a liquid to its gaseous (vapor) state, typically by heating the liquid to a temperature called its boiling point. The boiling of a substance is known as a phase change or phase transition. Chemically, the substance remains the same, but its physical state (or "phase") changes. The energy for phase change is generally supplied by the surface on which boiling occurs. Boiling differs from evaporation at predetermined vapor/gas-liquid interfaces because it also involves creation of these interfaces at discrete sites on the heated surface. Boiling is an extremely efficient process for heat removal and is utilized in various energyconversion and heat-exchange systems and in the cooling of high-energy density components, i.e. Boiler, Steam generators, water tube boiler, heat exchangers, heat recovery steam generators and nuclear power plant steam generators.

Heat transfer phenomena associated with liquid vapour phase change play an important role in boiling process as in water tube boiler, heat exchangers, heat recovery steam generators and nuclear power plant steam generators. The objective of this work is to enhance the boiling heat transfer of compressed water enters a vertical tube and leaves near saturation vapor conditions while the tube is heated with stream of cross tube hot gases. This is carried out by employing different types of internal tube coatings with different surface roughnesses and different internal coating thicknesses.

The model also aims at obtaining the non-uniform heat flux and wall temperature along the tube height. The boiling heat transfer enhancement is carried out by using different materials with different surface roughness as an internal coating inside

${ }^{*}$ Corresponding author. Tel.: +20122116611

Fax: +20233362433; E-mail: khalile1@asme.org

(C) 2010 International Association for Sharing Knowledge and Sustainability

DOI:10.5383/ijtee.02.02.004 the inner surface of the vertical tube. Moreover, this work is used to define the most adequate heat transfer models form used in the different flow regions and also define the surface roughness and coating thickness which give more enhancements for the heat transfer mechanism.

The scope of the present work can be summarized:

- The effect of using different surface roughness conditions $(\varepsilon / \mathrm{D})$ to enhance the flow boiling will be investigated.

- The effect of using different internal coating thicknesses $(\delta)$ to enhance the flow boiling will be analyzed.

- The required heated vertical tube length for predetermined inlet, outlet flow and boundary conditions.

\section{Mathematical Model}

\subsection{Physical Model}

The model describes the situation where water enters a vertical tube as compressed liquid with certain temperature and pressure and leaves at low vapor quality values whereas an external hot gases stream perpendicular to the tube supplies the heat flux required to the evaporation process. Temperature and velocity of hot gases is considered uniform which are thus leading to non uniform wall temperature and heat flux along the tube length. Figure 1 illustrates the test case which is a tube with inlet diameter $2.6(\mathrm{~cm})$ having inlet water with mass flux (G) equal to $47.2\left(\mathrm{~kg} / \mathrm{s} . \mathrm{m}^{2}\right)$ and the hot flow stream outside the tube and perpendicular to the tube has a uniform temperature 
$\mathrm{T}_{\mathrm{g}}$ is equal to $140\left({ }^{\circ} \mathrm{C}\right)$ and uniform equivalent heat transfer coefficient $h_{\text {ge }}$ equal to $600\left(\mathrm{~W} / \mathrm{m}^{2} . \mathrm{K}\right)$ which will be explained later in the heat transfer equation.

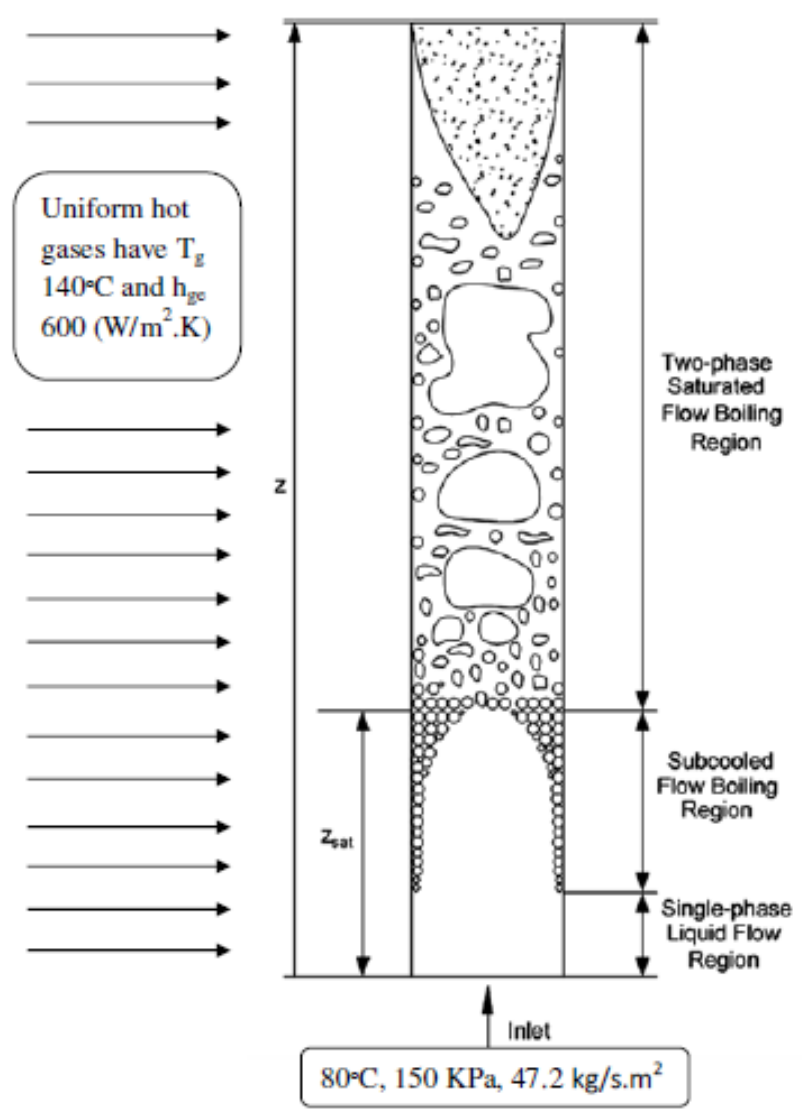

Fig. 1. Single-phase liquid flow, subcooled flow boiling and twophase saturated flow boiling [1]

The boiling enhancement internal surface paint used for the present surface treatment was a mixture of $1.5(\mathrm{gm})$ of silver flakes $(3-10)(\mu \mathrm{m}), 0.1(\mathrm{ml})$ of omega bond 101 thermal epoxy and $10(\mathrm{ml})$ of isopropyl alcohol. This paint composition was determined by conducting a study that systematically varied the silver flakes content in the mixture and was found to provide the highest level of enhancement throughout the boiling curve by O'Connor [2]. The paint was applied to the reference surface using a dripping technique and then the paint was cured under a lamp at $80\left({ }^{\circ} \mathrm{C}\right)$ for 100 (minutes), during cure, the alcohol evaporated and the mixture of flakes and epoxy adheres to the surface.

\subsection{Simplifying Assumptions}

- Conservation of mass.

- Conservation of momentum.

- Conservation of energy.

- Heat transfer correlation.

\subsection{General Governing Equations}

Applying the well-known equations of conservation mass, momentum and energy as following:

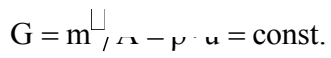

Where $G$ is the water mass flux or mass velocity, $m$ is the water mass flow rate, $\mathrm{A}$ is the cross sectional area of the vertical tube, $\rho$ is the water density and $u$ is the water vertical velocity in the $\mathrm{z}$ direction.

$$
-\frac{d p}{d z}=\rho \cdot g+2 \cdot f \cdot \frac{G^{2}}{\rho \cdot D_{h}}+G \cdot \frac{d u}{d z}
$$

Where $(\mathrm{dp} / \mathrm{dz})$ is the pressure drop of the water flow along the vertical direction, $g$ is the acceleration of gravity, $f$ is the flow friction factor, $D_{h}$ is the hydraulic diameter of the tube and $(\mathrm{du} / \mathrm{dz})$ is the velocity variation along the $\mathrm{z}$ direction.

$$
\mathrm{A} \cdot \mathrm{G} \cdot \frac{\mathrm{d}\left(\mathrm{i}+\mathrm{u}^{2} / 2+\mathrm{g} \cdot \mathrm{z}\right)}{\mathrm{dz}}=\pi \cdot \mathrm{D}_{\mathrm{h}} \cdot \mathrm{U} \cdot\left(\mathrm{T}_{\mathrm{g}}-\mathrm{T}_{\mathrm{b}}\right)
$$

Where $\mathrm{i}$ is the flow enthalpy, $\mathrm{U}$ is the overall heat transfer coefficient and $T_{b}$ is the bulk temperature of the water flow. While the overall heat transfer coefficient can be expressed by:

$$
\frac{1}{\mathrm{U}}=\frac{1}{\mathrm{~h}_{\mathrm{f}}}+\Sigma \mathrm{R}_{\text {fouling }}+\Sigma \mathrm{R}_{\text {cond. }}+\frac{1}{\left(\mathrm{~A}_{\mathrm{o}} / \mathrm{A}_{\mathrm{h}}\right) \cdot \mathrm{h}_{\mathrm{g}}}
$$

Where $h_{f}$ is the heat transfer coefficient of the internal flow, $D_{o}$ and $D_{h}$ are the inner outer tube diameters respectively, $A_{o}$ and $A_{h}$ are the vertical tube surface area corresponding to it inner and outer radiuses and $h_{g}$ is the heat transfer coefficient of the hot stream outside gases. The term $\left(\mathrm{A}_{\mathrm{o}} / \mathrm{A}_{\mathrm{h}}\right) \cdot \mathrm{h}_{\mathrm{g}}$, which is considered as an equivalent heat transfer coefficient, is simplified by assigning it a fixed value $\left(\mathrm{h}_{\mathrm{ge}}\right)$, estimated in base to experimental data which is equal to $600\left(\mathrm{~W} / \mathrm{m}^{2} . \mathrm{K}\right)[1]$

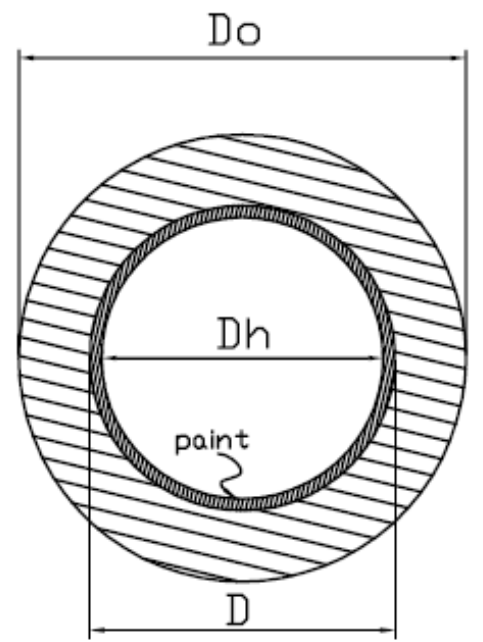

Fig. 2. Tube cross sectional area

According to the conduction resistances it was due to the tube material and due to coating which has a thermal conductivity ( $\mathrm{k}_{\text {coating }}$ ) of 0.95 (W/m.K) as defined by O'Connor [2] and according to the fouling resistances it were because of the outside hot flue gases $\left(\mathrm{R}_{\text {flue, fouling }}\right)$ which was equal to 0.002 $\left(\mathrm{m}^{2} . \mathrm{K} / \mathrm{W}\right)$ which is tabulated in Lienhard [3] and the internal flow boiling $\left(\mathrm{R}_{\text {flow, fouling }}\right)$ which was equal to $0.0002\left(\mathrm{~m}^{2} . \mathrm{K} / \mathrm{W}\right)$ which is tabulated in Lienhard [3]. While the heat flux represented by the following equation along the tube length:

$$
\mathrm{q}=\mathrm{h}_{\mathrm{ge}}\left(\mathrm{T}_{\mathrm{g}}-\mathrm{T}_{\mathrm{w}}\right)
$$


Where (q) is heat flux which is not uniform but both $h_{g e}$ and $T_{g}$ are remaining uniform along the tube. Dividing the vertical tube length into three regimes which are liquid single-phase, subcooled boiling and two-phase saturated boiling. While the subcooled flow boiling regime is divided into three sub regimes which are partial flow boiling, fully developed boiling and significant void flow.

\subsubsection{Liquid Single-Phase Regime}

Because the water enters the tube below its boiling point as a compressed liquid, so the variations of the liquid density with the z-axis can be neglected so the velocity can be taken as constant, then the conservation of mass will be Eq.1 and the conservation of momentum will be.

$$
-\frac{\mathrm{dp}}{\mathrm{dz}}=\rho_{\mathrm{L}} \cdot \mathrm{g}+2 \cdot \mathrm{f}_{\mathrm{L}} \cdot \frac{\mathrm{G}^{2}}{\rho_{\mathrm{L}} \cdot \mathrm{D}_{\mathrm{h}}}
$$

While the friction factor $f_{\mathrm{L}}$ for fully developed turbulent flow is calculated by the Romeo et al. correlation [4].

And the energy conservation become as follow:

$$
A \cdot G \cdot\left[\frac{d\left(c_{P L} \cdot T_{b}\right)}{d z}+\frac{1}{\rho_{L}} \cdot \frac{d p}{d z}+g\right]=\pi \cdot D_{h} \cdot U \cdot\left(T_{g}-T_{b}\right)
$$

Where $\mathrm{cpL}$ is the liquid water specific heat. To get the overall heat transfer coefficient (U) use the Dittus-Boelter correlation [5] to get the pure single-phase liquid heat transfer coefficient of water as follow:

$$
\mathrm{h}_{\mathrm{f}}=\mathrm{h}_{\mathrm{L}}=0.023 \operatorname{Re}^{0.8} \operatorname{Pr}_{\mathrm{L}}^{0.4}\left(\frac{\mathrm{k}_{\mathrm{L}}}{\mathrm{D}_{\mathrm{h}}}\right)
$$

Where $\operatorname{Pr}_{\mathrm{L}}$ is the Prandtl number and $\mathrm{k}_{\mathrm{L}}$ is the liquid water thermal conductivity.

\subsubsection{Two-Phase Saturated Flow Boiling Regime}

Eq.1 which represent the conservation of mass for this regime while the conservation of momentum and using the separated flow model will be as follow:

$$
\begin{aligned}
& -\frac{d p}{d z}=\left[\alpha \cdot \rho_{V}+(1-\alpha) \cdot \rho_{L}\right] \cdot g+\phi_{L}^{2} \cdot\left[2 \cdot f_{L} \cdot \frac{G^{2}(1-x)^{2}}{\rho_{L} \cdot D_{h}}\right]+ \\
& G^{2} \cdot \frac{d}{d z}\left(\frac{x^{2}}{\alpha \cdot \rho_{V}}+\frac{(1-x)^{2}}{(1-\alpha) \cdot \rho_{L}}\right)
\end{aligned}
$$

Where $\alpha$ is the void fraction or volumetric vapor content, $\mathrm{x}$ is the steam quality and to determine the pressure variation along the tube, the Lockhart \& Martinelli generalized correlation method has been followed [6,7], in the case which is under study each phase is flowing alone in the tube would be turbulent so the relation for the two-phase multiplier $\left(\varphi_{\mathrm{L}}\right)$ will be:

$$
\phi_{\mathrm{L}}^{2}=1++20 / \mathrm{X}_{\mathrm{tt}}+1 / \mathrm{X}_{\mathrm{tt}}^{2}
$$

$$
\begin{aligned}
& X_{\mathrm{tt}}=\left(\frac{\rho_{\mathrm{V}}}{\rho_{\mathrm{L}}}\right)^{0.5}\left(\frac{\mu_{\mathrm{L}}}{\mu_{\mathrm{V}}}\right)^{0.125}\left(\frac{1-\mathrm{x}}{\mathrm{x}}\right)^{0.875} \\
& \alpha=\left[1+0.28 \mathrm{X}_{\mathrm{tt}}^{0.71}\right]^{-1}
\end{aligned}
$$

Where $\mathrm{X}_{\mathrm{tt}}$ is Martinelli parameter.

While the energy Eq.2 for the two-phase saturated boiling regime will be:

$$
\begin{aligned}
& A \cdot G \frac{\partial}{\partial z}\left\{x\left(\frac{G^{2} x^{2}}{2 \rho_{v}^{2} \alpha^{2}}\right)+i_{L}+(1-x)\left[\frac{G^{2}(1-x)^{2}}{2 \rho_{L}^{2}\left(1-\alpha^{2}\right)}\right]+x\left(i_{v}-i_{L}\right)\right\} \\
& +A \cdot G \frac{\partial}{\partial z}(z \cdot g)=\pi \cdot D_{h} \cdot U \cdot\left(T_{g}-T_{\text {Sat. }}\right)
\end{aligned}
$$

Where $\mathrm{T}_{\text {Sat. }}$ is the water flow saturation temperature. For simplicity, the kinetic term $\left(\mathrm{u}^{2} / 2\right)$ can be neglecting compared to the enthalpy terms $\left[i_{L}, x\left(i_{V}-i_{L}\right)\right]$. To get the overall heat transfer coefficient (U) using the Kandlikar correlation [8] to get the water heat transfer coefficient which is two-phase for water inside smooth vertical tubes as follow:

$$
\frac{h_{f}}{h_{L}}=\frac{h_{\text {tp }}}{h_{L}}=\left\{\begin{array}{lll}
1.136 \mathrm{Co}^{-0.9}+667.2 \mathrm{Bo}^{0.7} & \text { for } & \mathrm{Co} \prec \\
0.6683 \mathrm{Co}^{-0.2}+1058 \mathrm{Bo}^{0.7} & \text { for } & \mathrm{Co} \succ
\end{array}\right.
$$

$$
\begin{aligned}
& \mathrm{Bo}=\frac{q}{\mathrm{G} \cdot \mathrm{i}_{\mathrm{LV}}} \\
& \mathrm{Co}=\left(\frac{1-\mathrm{x}}{\mathrm{x}}\right)^{0.8}\left(\frac{\rho_{\mathrm{V}}}{\rho_{\mathrm{L}}}\right)^{0.5}
\end{aligned}
$$

Where $\mathrm{h}_{\mathrm{tp}}$ is the two-phase heat transfer coefficient, Co is the convection number, Bo is the boiling number, $\mathrm{q}$ is the heat flux and $i_{L V}$ is the latent heat of vaporization. To calculate $h_{L}$ from Eq.8, put Reynolds number in the form:

$$
\operatorname{Re}=\frac{G \cdot(1-x) \cdot D_{h}}{\mu_{L}}
$$

\subsubsection{Subcooled Flow Boiling Regime}

Subcooled flow boiling zone are divided into three different sub-regimes which are as shown in figure 3:

- Partial boiling from ONB to FDB.

- Fully developed boiling from FDB to OSV.

- Significant void flow or net vapor generation from OSV to saturation. 


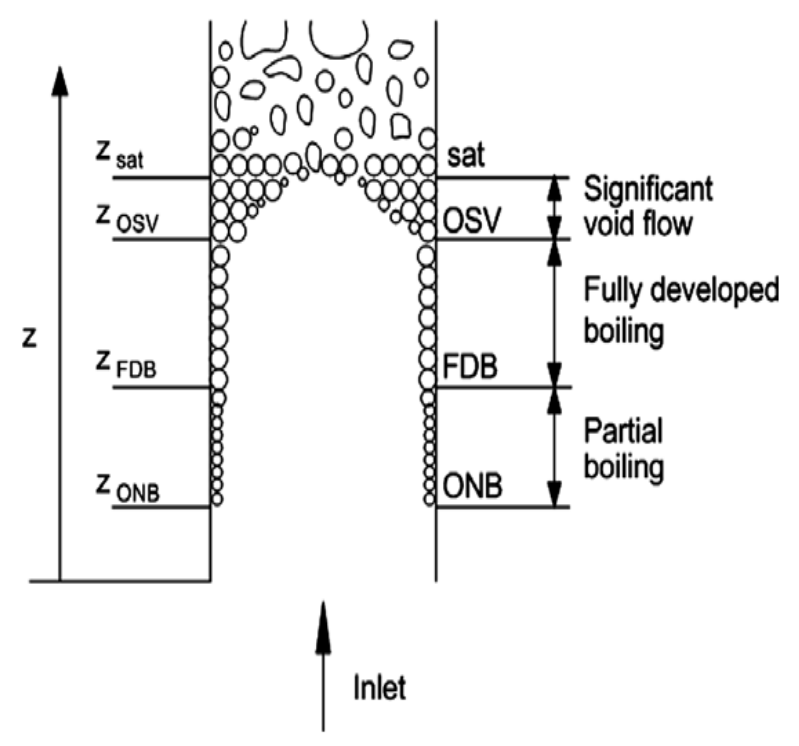

Fig. 3. Subcooled flow boiling in details [1]

In summery partial boiling and fully developed boiling (from ONB to OSV) are highly subcooled so the continuity, momentum and energy equations would be the same of the liquid single-phase regime Eqs.1, 6 and 7 and the significant void flow or net vapor generation (from OSV to saturation) is low subcooled so the continuity, momentum equations would be the same of the two-phase saturated flow boiling regime Eqs. 1 and 9 and energy equation will be the same of the liquid single-phase regime Eq.7, all significant void flow or net vapor generation region equations work with the apparent quality $\left(\mathrm{x}_{\mathrm{a}}\right)$ which was used by Saha and Zuber correlations [9] as function of the non-equilibrium for the NVG or OSV point.

To get the overall heat transfer coefficient (U) using the Zambrana et al. correlation [1] to get the water heat transfer coefficient which is subcooled water inside smooth vertical tubes, it is an elliptical expression as function of the two ends which are pure liquid and saturated flow, the relation is as follow:

$$
\begin{aligned}
& h_{f}=h_{L}=h_{\text {Lso }}-\sqrt{\frac{(B+Z)\left(Z_{\text {Sat. }}-Z\right)}{\left(B+Z_{o}\right)\left(Z_{\text {Sat. }}-Z_{o}\right)}}\left(h_{\text {Lso }}-h_{\text {Lo }}\right) \\
& B=-Z_{o}+\frac{Z_{\text {Sat. }}-Z_{o}}{1-\frac{2 a\left(Z_{\text {Sat. }}-Z_{o}\right)}{\left(h_{\text {Lso }}-h_{L o}\right)}} \\
& a=\left(\frac{d h_{L}}{d z}\right)_{z=z_{o}}
\end{aligned}
$$

Where $\mathrm{h}_{\mathrm{LSo}}$ is the heat transfer coefficient at the flow saturation point which is $Z_{\text {Sat. }}$ and $\mathrm{h}_{\mathrm{Lo}}$ is the heat transfer coefficient at onset nucleate boiling which is $Z_{0}$.

The heat transfer coefficient $\left(\mathrm{h}_{\mathrm{LSo}}\right)$ was predicted by Kandlikar correlation [8] at the point of vapor quality zero $\left(\mathrm{Z}_{\text {Sat. }}\right)$ using Eqs.14 and 15, and The heat transfer coefficient $\left(\mathrm{h}_{\mathrm{Lo}}\right)$ was predicted by Dittus-Boelter correlation [5] at the onset nucleate boiling point $\left(\mathrm{Z}_{\mathrm{o}}\right)$ using Eq.8.

\subsection{Performance Analysis}

To determine if the coating improve the heat transfer of the system or not, Colburn factor (j) will be calculated and then plotted versus Reynolds number (Sadik Kakaç [10]), where Colburn factor equal to:

$$
\begin{aligned}
& j=S t \cdot \operatorname{Pr}^{2 / 3} \\
& S t=\frac{h}{G \cdot c_{p}} \\
& \operatorname{Pr}=\frac{c_{p} \cdot \mu}{k}
\end{aligned}
$$

Where St is the Stanton number and Pr is the Prandtl number. As the colburn factor increase this mean improvement of heat transferring system.

According to the previous equations for the four different water flow regimes which are liquid single phase (from inlet till onset nucleate boiling), partial and fully developed boiling (from onset nucleate boiling till OSV), significant void flow or net vapor generation (from OSV till saturation) and two-phase saturated flow boiling (from saturation till required steam quality).

To solve these equations professional computerized program used called Engineering Equation Solver (EES) [11]. For further details reference can be made to the work of Abdel Azim [12].

\subsection{Boundary, Inlet and Physical Conditions}

Table 1 summarized the boundary, inlet and physical

\begin{tabular}{|c|c|c|c|}
\hline Item & Type & Symbol (unit) & Value \\
\hline Water temperature & inlet & $\mathrm{T}_{\mathrm{i}}\left({ }^{\circ} \mathrm{C}\right)$ & 80 \\
\hline Water pressure & Inlet & $\mathrm{P}_{\mathrm{i}}(\mathrm{KPa})$ & 150 \\
\hline Water mass flux & Inlet & $\mathrm{G}\left(\mathrm{kg} / \mathrm{m}^{2} . \mathrm{s}\right)$ & 47.2 \\
\hline Final steam quality & Inlet & $\mathrm{x}\left(\mathrm{kg}_{\text {st. }} / \mathrm{kg}_{\text {total }}\right)$ & $20 \%$ \\
\hline Hot gases temperature & Boundary & $\mathrm{T}_{\mathrm{g}}\left({ }^{\circ} \mathrm{C}\right)$ & 140 \\
\hline $\begin{array}{l}\text { Equivalent heat transfer } \\
\text { coefficient }\end{array}$ & Boundary & $h_{\text {eg }}\left(W / m^{2} . K\right)$ & 600 \\
\hline Tube diameter & Physical & $\mathrm{D}(\mathrm{cm})$ & 2.6 \\
\hline
\end{tabular}
conditions for the case under study which is consists of vertical tube heated by hot gases with uniform temperature and heat transfer coefficient while subcooled water enter the vertical tube from its bottom.

Table 1. Boundary, inlet and physical conditions

\section{Results and Discussions}

This study has been developed for water pressure near to ambient and final low steam quality value it can be near to operating conditions of the low pressure level of a heat recovery steam generator (HRSG), but with enough subcooling to detect the ONB. 
Results of water subcooled flow boiling are obtained for cases of no coating is used and for five different coating thicknesses ( $\delta)$ which are $(25,45,61,93$ and $124 \mu \mathrm{m})$ in each case four different surface roughness dimensionless groups $(\varepsilon / \mathrm{D})$ which are $(0.05,0.01,0.001$ and 0.0001$)$ and for the inlet and physical boundary conditions as illustrated in table 1 .

\subsection{Comparison of All Boiling Regimes for Four Different Surface Roughness Results}

This samples of the results for this section were taken for internal surface coating thickness of $25(\mu \mathrm{m})$ and the surface roughness dimensionless groups $(\varepsilon / D)$ which were $(0.05,0.01$, 0.001 and 0.0001 ).

Figure 4 illustrate the difference between the four surface roughnesses coefficients on the flow friction factor estimation.

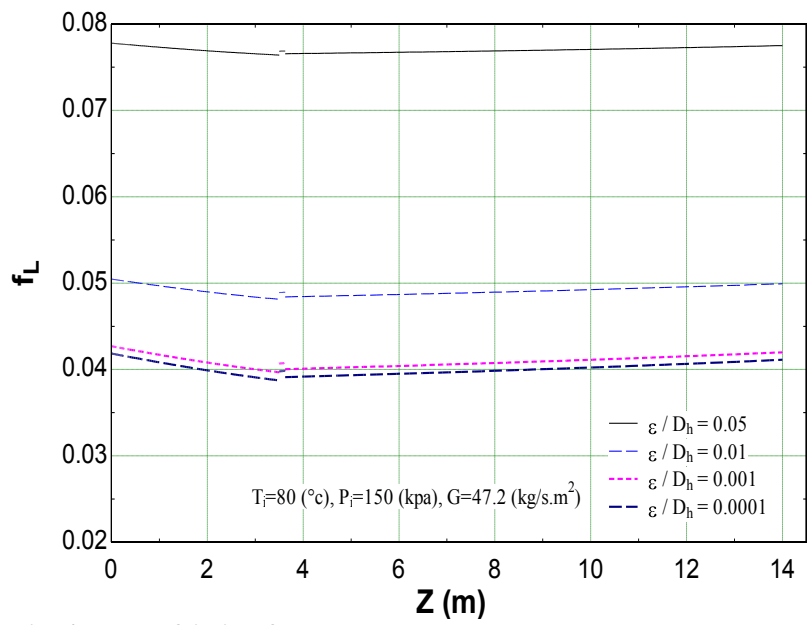

Fig. 4. Flow friction factor versus tube length

Using internal surface coating with different surface roughnesses coefficients make enhancement for the boiling process as Investigation shows in Figure 5 that the heat transfer coefficient is nearly a straight line in the regime of two-phase saturated flow boiling.

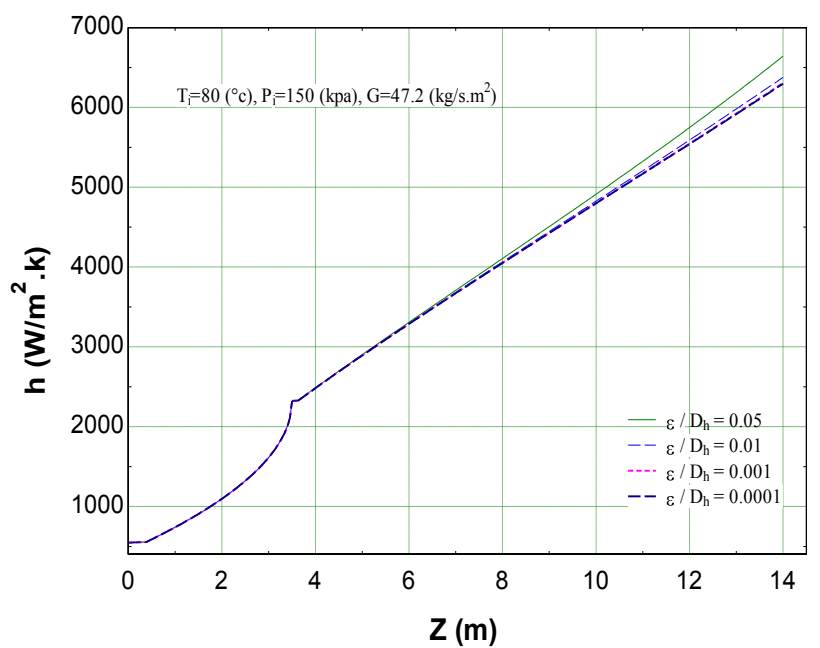

Fig. 5. Heat transfer coefficient versus tube length

The four different cases did not differ for the single-phase and subcooled flow boiling, the noticeable difference occurred in the saturated two-phase flow boiling where the surface roughness $(\varepsilon / D)$ of 0.05 resulted in the largest value of the heat transfer coefficient. Because of for higher surface roughness, more cavity places for initiating the steam bubbles over the tube surface, which will gives more steam, which has higher velocity than liquid so the heat transfer coefficient will be increased.While the overall heat transfer coefficient doesn't show in figure 6 any noticeable difference for the four surface roughness cases for all flow boiling regimes.

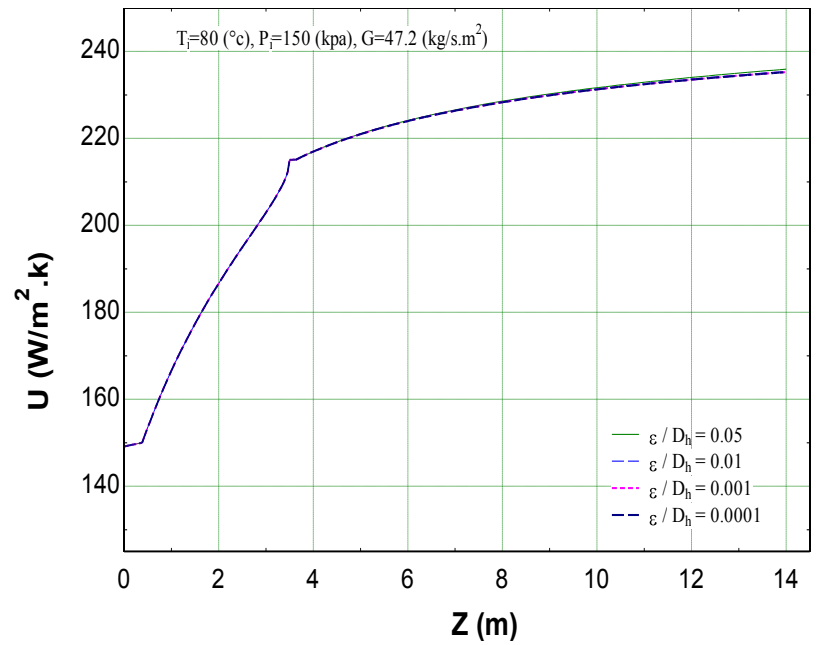

Fig. 6. Overall heat transfer coefficient versus tube length

Because of the hot gases have uniform temperature and heat transfer coefficient along the vertical heated tube Figure 7 shows that the heat flux in this case is not uniform along the vertical tube length; the heat flux is increased with the flow direction. The noticeable different occurred in the saturated two-phase flow boiling where the surface roughness $(\varepsilon / D)$ of 0.05 resulted in the largest value of the heat transfer coefficient which give more turbulence because of there are more cavities to enhance boiling process. As the value of the surface roughness decreased, this difference diminished.

For judgment on the improvement occurred on the boiling heat transfer, Colburn factor is an indication if the boiling heat transfer was improved or not due to the usage of the rough surface, figure 8 shows Colburn factor increases due to the rough coated surface which mean improvement in the boiling heat transfer process.

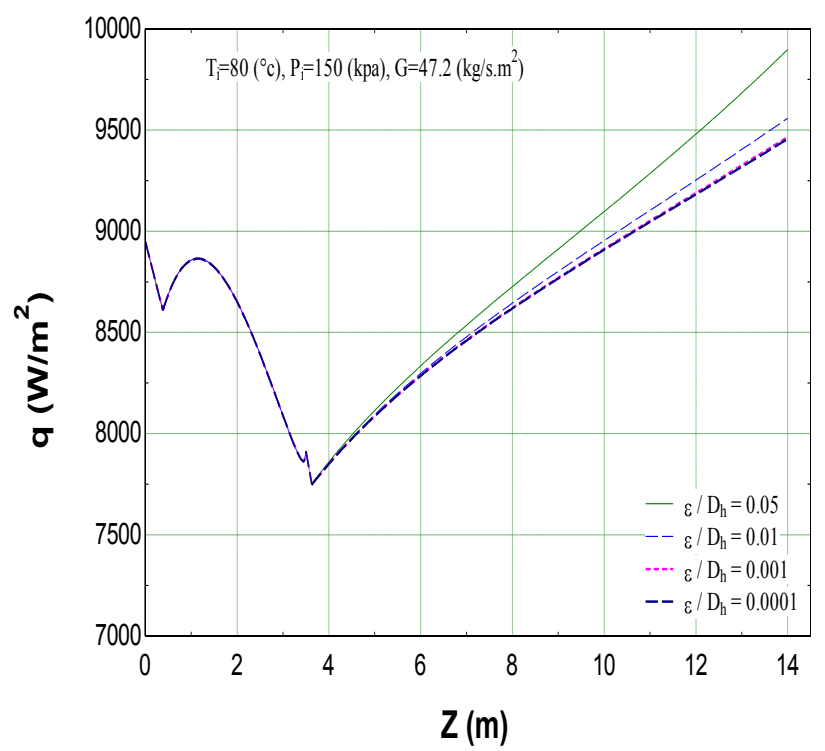

Fig. 7. Heat flux versus tube length 


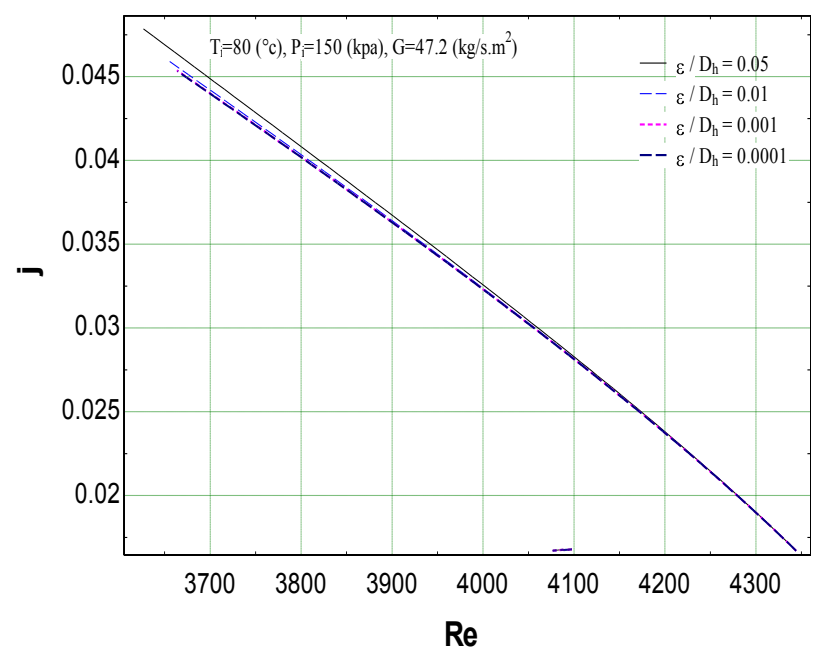

Fig. 8. Colburn factor (j) versus Reynolds (Re)

\subsection{Comparison of All Boiling Regimes for Four Different Coating Thicknesses Results}

The samples of the results for this section were taken for no coating and different coating thicknesses of $(25,45,61,93$ and 124) $(\mu \mathrm{m})$ and the surface roughness dimensionless group $(\varepsilon / \mathrm{D})=0.05$

Figures 9 and 10 show that by increasing the internal coating thickness heat transfer coefficient, heat flux and overall heat transfer coefficient will be decreased because of the increase of the conduction thermal resistance of the internal coated material.

It was indicated in figures 12 to 14 that the boiling heat transfer coefficient, overall heat transfer coefficient and heat flux decrease as increasing the internal coating to due add more thermal conduction resistance facings the heat flux crossing the heated tube thickness.

\subsection{Parameters Variations of All Boiling Regimes}

This samples of the results for this section were taken for tube thickness of $25(\mu \mathrm{m})$ and the surface roughness dimensionless group $(\varepsilon / \mathrm{D})=0.05$

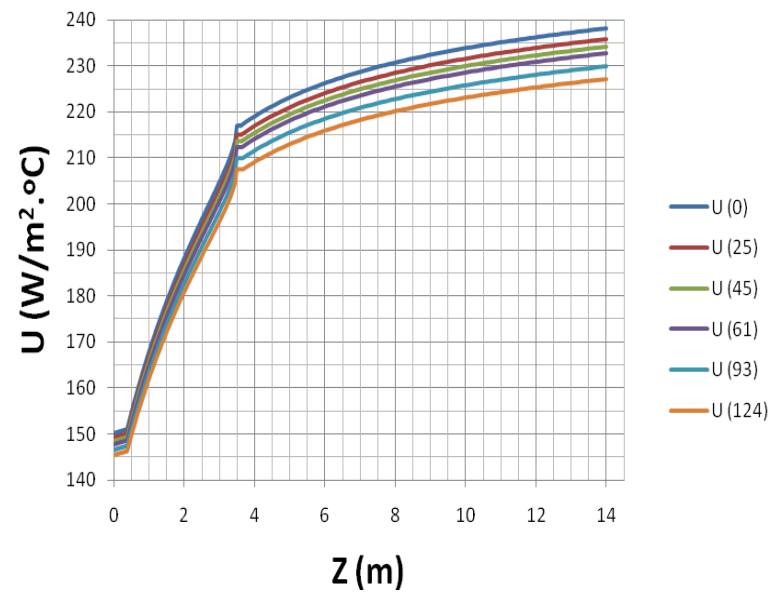

Fig. 10. Overall heat transfer coefficient versus tube length

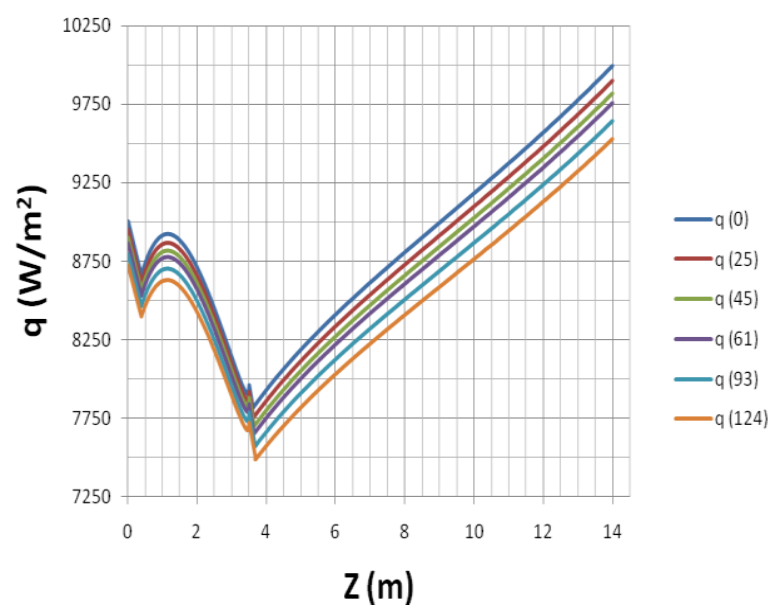

Fig. 11. Heat flux versus tube length

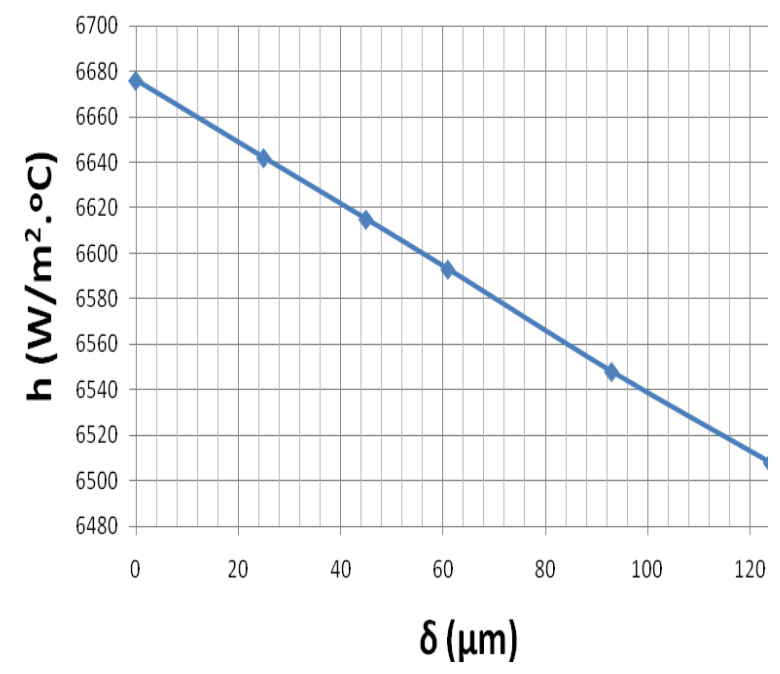

Fig. 12. Heat transfer coefficient versus coating thickness

Figure 15 illustrate the heat transfer coefficient of the water flow inside the heated tube and also the heat flux passes through the tube wall. It is clearly in this figure that the heat flux distribution along the vertical heated tube is non-uniform and varies depending on the boiling heat transfer mechanisms

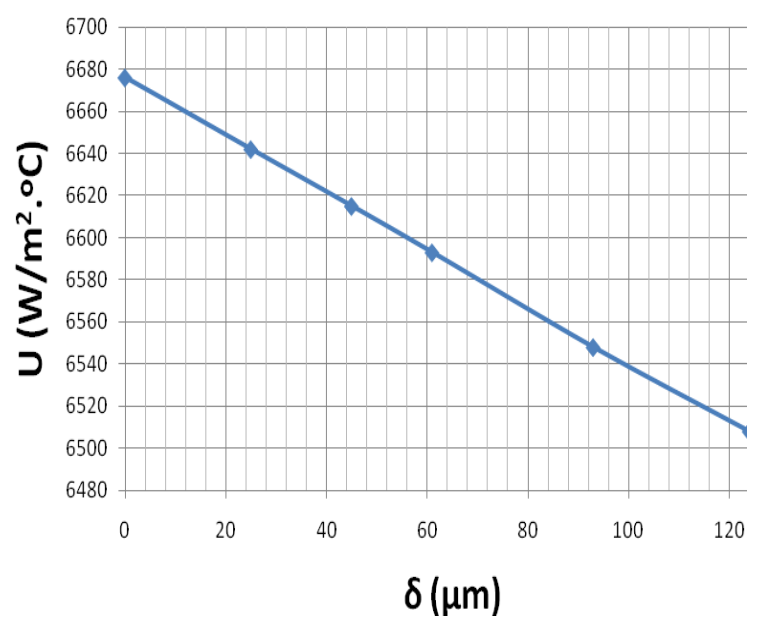

Fig. 13. Overall heat transfer coefficient versus coating thickness 


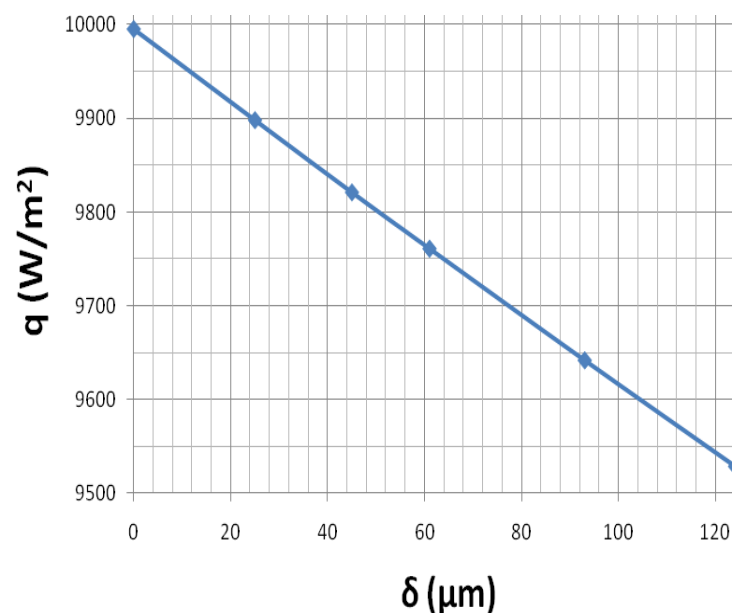

Fig. 14. Heat flux versus coating thickness

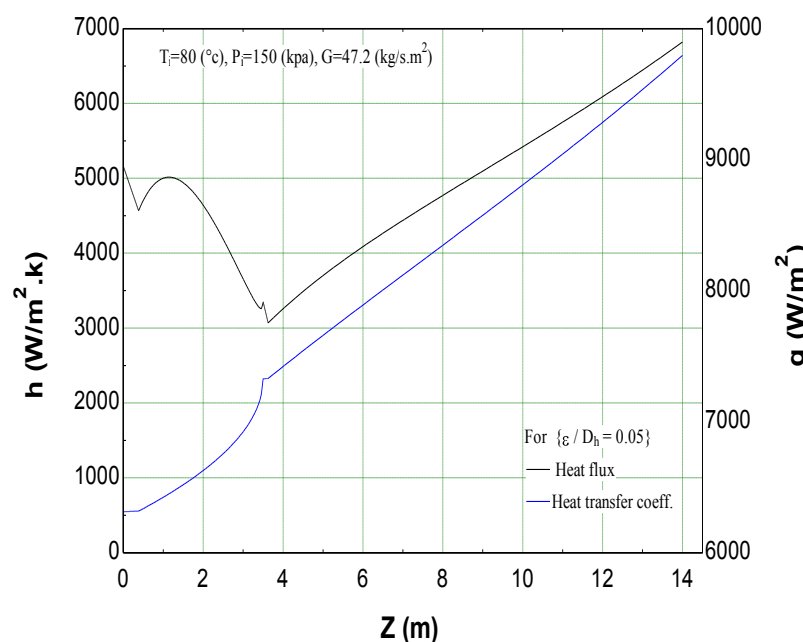

Fig. 15. Heat transfer coefficient and heat flux versus tube length

\section{Conclusions}

It was concluded that the required tube length was $14(\mathrm{~m})$ to get the prescribed outlet conditions with the predetermined inlet and boundary conditions.

By changing the surface roughness coefficient for certain internal surface coating thickness it was noticed that most of the results investigated has heat transfer enhancement for the surface roughness value of 0.05 , noticed in the figures 5 to 8 .

While when internal coating thickness changed for constant value of the surface roughness shows that increasing the internal coating has a bad effect on the boiling heat transfer process which results on decreasing the amount of produced steam at the exit section of the heated tube because of heat flux and heat transfer coefficient decreased. So not using internal surface coating will give highest value for heat flux and amount of produced steam, but it is necessary to use coating for boiling initiating and for chemical corrosion so it was found that using coating thickness of $25(\mu \mathrm{m})$ will be efficient.

Finally it was concluded from this results of this work that heat transfer process is enhanced for the internal coating thickness of $25(\mu \mathrm{m})$ and surface coating coefficient of 0.05 .

\section{Nomenclature}

A

$c_{p}$

D

EES

$f$

$\mathrm{G}$

$\mathrm{g}$

h

i

$\mathrm{k}$

$\mathrm{m} \cdot$

NVG

ONB

OSV

$\mathrm{p}$

PB

$\mathrm{q}$

R

SVF

$\mathrm{T}$

$\mathrm{U}$

$\mathrm{u}$

$\mathrm{x}$

\section{Greek Symbols}

$\Delta \quad$ Change interval of any property

$\rho \quad$ Mass density, $\mathrm{kg} / \mathrm{m}^{3}$

$\delta \quad$ Coating thickness, $\mu \mathrm{m}$

$\eta \quad$ Fin efficiency

$\mu \quad$ Dynamic viscosity, kg.m/s

$\alpha \quad$ Void fraction

$\varphi \quad$ Two-phase multiplier factor

$\varepsilon \quad$ Surface roughness, $\mathrm{m}$

\section{Subscripts}

b Flow bulk

Cond. Conduction resistance

$\mathrm{f}$ Convective

fL Full liquid

fouling Fouling resistance

g Gas

ge Gas equivalent

h Hydraulic

L Liquid

Lo All liquid

Lso Liquid saturated

o Outer

Sat. Saturation

Sub. Subcooled

TP Two phase

w Wall

Non-dimensional Numbers

Co Convective number

j Colburn factor

Pr Prandtl number

$\mathrm{Re} \quad$ Reynolds number

St Stanton number

$\mathrm{X}_{\mathrm{tt}} \quad$ Lockhart-Martinelli parameter 


\section{References}

[1] Zambrana, J., Leo, T. J. and Perez-del-Notario, P. Vertical tube length calculation based on available heat transfer coefficient expressions for the subcooled flow boiling region. Applied thermal Engineering 2008;28:499-513. doi:10.1016/i.applthermaleng.2007.05.003

[2] O'Connor, J. P. and You, S. M. A painting technique to enhance pool boiling heat transfer in saturated FC-72. ASME Journal Heat Transfer 1995;117:387-393. doi:10.1115/1.2822534

[3] Lienhard IV, J. H. and Lienhard V, J. H. A heat transfer text book. 2006 Phlogiston press.

[4] Romeo, E., Royo, C. and Monzón, A. Improved explicit equations for estimation of the friction factor in rough and smooth pipes. Chemical Engineering Journal 2002; 86:369-374. doi:10.1016/S1385-8947(01)00254-6

[5] Chapman, A.J. Heat Transfer. Collier McMillan, New York, 1994.

[6] Carey, V.P. Liquid-Vapour Phase-change Phenomena. Hemisphere Publishing Corporation, Washington, 1992:483-563.
[7] Lockhart, R.W., Martinelli, R.C. Proposed correlation of data for isothermal two-phase two-component flow in pipes. Chemical Engineering Prog. 1949; 4: 39-48.

[8] Kandlikar, S. G. A general correlation for two phase flow boiling heat transfer inside horizontal and vertical tubes. ASME Journal Heat Transfer 1990; 112:219-228 http.dx.doi.org/10.1115/1.2910348

[9] Saha, P., Zuber, N. Point of net vapour generation and vapour void fractions in subcooled boiling. Proceedings of the 5th International Heat Transfer Conference (1976), Tokyo, Paper B4.7.

[10] Kakaç, S., Cao, L. Analysis of convective two-phase flow instabilities in vertical and horizontal in-tube boiling systems. Int. Journal of Heat and Mass Transfer 2009; 52: 3984-3993.

http.dx.doi.org/10.1016/j.ijheatmasstransfer.2009.03.025

[11] Engineering Equation Solver Manual for Microsoft Windows Operating Systems Commercial and Professional Versions F-Chart Software Copyright 19922009 by S.A. Klein.

[12] Abdel Azim, A.Y., Heat Transfer and Pressure Drop of Subcooled Flow Boiling in Vertical Tubes with Internal Surface Coatings, MSc Thesis, Cairo University, July 2010. 